\title{
Determinants of Systemic Diseases amongst Periodontitis Patients in Suva, Fiji
}

Anjali Thomas ${ }^{1 *}$, Leenu Raju Maimanuku' ${ }^{2}$, Masoud Mohammadnezhad ${ }^{3}$ and Sabiha Khan ${ }^{4}$

${ }^{1}$ Department of Public Health, School of Public Health and Primary Care, Fiji National University, Fiji

${ }^{2} S c h o o l ~ o f$ Dentistry and Oral Health, College of Medicine, Nursing and Health Sciences, Fiji National University, Fiji

${ }^{3}$ Department of Public Health, School of Public Health and Primary Care, Fiji National University, Fiji

${ }^{4}$ Department of Statistics, School of Public Health and Primary Care, Fiji National University, Fiji

"Corresponding author: Anjali Thomas, School of Public Health and Primary Care, Fiji National University, Fiji, Tel: +6793381044; E-mail: anjalithomas23@gmail.com Received date: March 22, 2018; Accepted date: March 29, 2018; Published date: April 05, 2018

Copyright: @ 2018 Thomas A, et al. This is an open-access article distributed under the terms of the Creative Commons Attribution License, which permits unrestricted use, distribution, and reproduction in any medium, provided the original author and source are credited.

\begin{abstract}
Introduction: Periodontitis develops through opportunistic infection which usually occurs when there is an imbalance between the oral biofilm and host defense's and has been connected with various systemic diseases such as heart diseases, diabetes, renal diseases, respiratory diseases etc. Due to lack of previous study, this study is aimed to describe the determinants of systemic diseases amongst periodontitis patients in Suva, Fiji.

Methodology: This retrospective descriptive study was carried out in the FNU Dental Clinics, Suva, Fiji using the periodontitis patient clinical records from 1st January 2013 to 31st December 2014. Periodontitis patients with or without self-reported systemic disease history were included in this study. Patient demographic variables were collected and Binary logistic regression was used to calculate odds ratio with their $95 \%$ Confidence Intervals to define any association between dependent variable and independent variables. A $p$-value $<0.05$ was considered statistically significant.
\end{abstract}

Results: The results of the study showed that the odds of having systemic disease were 3.5 times higher in 40-64year-old patients than in the 15-39-year-old periodontitis patients (OR $3.5,95 \% \mathrm{Cl} 1.98-6.09, p=<0.001$ ). Male periodontitis patients reported with $42 \%$ systemic disease and females reported with $58 \%$ systemic disease. Systemic disease was higher in females than males; however, this was not statistically significant. The odds of having systemic disease were 1.9 times higher in the Fijians of Indian Descent than among the I-Taukei Fijians (OR $1.9,95 \% \mathrm{Cl}: 1.17-3.11, \mathrm{p}=0.026)$.

Conclusion: The study concluded that systemic disease was the most in 40-64-year-old Fijians of Indian decent periodontitis patients, this was statistically significant. Female periodontitis patients showed higher presence of systemic diseases than the male periodontitis patients; however this was not statistically significant.

Keywords: Determinants; Periodontitis; Systemic diseases; Fiji

\section{Introduction}

Periodontitis develops through opportunistic infection which usually occurs when there is an imbalance between the oral biofilm and host defense's [1]. After dental decay, periodontal disease is considered as the second most common dental disease globally. In the United States $30-50 \%$ of the populations have periodontal disease, but only about $10 \%$ have severe forms of the disease. In 2010, it was estimated that about 750 million people or $10.8 \%$ of the population worldwide were affected by chronic periodontitis [2]. Periodontitis has been connected to a number of systemic diseases such as heart diseases, diabetes, renal diseases, respiratory diseases etc.

The prevalence of severe periodontal destruction increases with age, from 8 percent among adults 30 to 39 years of age to 35 percent among persons 60 to 69 years of age [3]. In a study by Georgiou et al. [4], the younger age groups (20-39) reported $40-50 \%$ of systemic conditions whereas among the older age groups the occurrence of systemic diseases was increased to $70-71.3 \%$. And in a study by Agarwal et al.
[5] it was reported that $72.78 \%$ periodontitis patients above the age of 60 years reported with some type of systemic disease.

Several studies have found associations between gender and some systemic diseases in periodontitis patients. In the study by Georgiou et al. [4] it was reported that males with periodontitis had higher prevalence of heart diseases than females. Few studies have also shown that gender have no association between some systemic diseases in periodontitis patients. According to Bhateja [6] 199 male patients (53.06\%) and 176 female patients (46.93\%) from patient records, almost all categories, except in the Cardiovascular and Gastrointestinal diseases, evoked male predilection over female patients with systemic diseases and was statistically insignificant $(\mathrm{P}>0.05)$.

In Fiji, increase in the number of people suffering from systemic diseases and death due to systemic diseases present one of the major challenges for the countries health systems. In 2010, the main causes of morbidity in Fiji were circulatory diseases (44\%), endocrine (13\%), and neoplasm's (10\%) [7]. According to the World Health Organization (WHO) 2014 updates the top causes of death in Fiji were coronary heart disease (24.23\%) and diabetes mellitus (17.76\%), respectively. 
Citation: Thomas A, Maimanuku LR, Mohammadnezhad M, Khan S (2018) Determinants of Systemic Diseases amongst Periodontitis Patients in Suva, Fiji. J Health Educ Res Dev 6: 254. doi:10.4172/2380-5439.1000254

Page 2 of 4

While death caused due to asthma was $2.41 \%$, kidney disease was $2.38 \%$, lung disease was $1.57 \%$ and liver disease was $1.15 \%$ [8].

A last published survey of oral health in Fiji showed the increase in number of patients suffering from increased periodontal diseases. According to the 2004 oral health survey report in Fiji; a widespread increase of periodontal disease was detected. Only $4.3 \%$ had healthy status, $67.1 \%$ showed presence of calculus, $19 \%$ shallow pockets, $4.1 \%$ deep pockets and about $3.3 \%$ had bleeding. Despite the increase of number of systemic diseases and periodontal diseases no study was done regarding occurrence of systemic diseases and periodontal diseases in Fiji. Therefore, the main aim of this study was to describe the determinants of systemic diseases amongst periodontitis patients in Suva, Fiji.

\section{Methodology}

This retrospective study was conducted among periodontitis patients with complete self-reported systemic disease history from 1st January 2013 to 31st December 2014 in two Dental Clinics at FNU, Suva, Fiji. Periodontitis patients with or without self-reported systemic disease history were included in this study. Patients without periodontitis were excluded from this study. The total number of periodontitis patient records studied was 369 and were identified by names. To ensure confidentiality is kept at all times the patient records were de-identified by serial numbers such as 1,2 , and 3 and so on in a study log sheet. Complete patient data such as patient serial numbers, self-reported history of systemic disease, demographic variables, selfreported behavioral risk factors, Community Periodontal Index (CPI) scores and severity of periodontitis recordings were collected in an excel spread sheet.

The data was typed and stored electronically in password protected files that was only accessible to the researcher and supervisors for analysis. Periodontitis patients with or without self-reported systemic disease history were included in this study. Patients without periodontitis were excluded from this study. Those records with no periodontal charting and non-standard gingival recession measurements and non-standard probing pocket depth measurements were categorized as not recorded in this study. All the categorical variables were presented by numbers and percentages. Chi square test was used to determine the demographic pattern among the periodontitis patients with and without systemic disease. And Binary logistic regression was used to calculate odds ratio with their $95 \%$ Confidence Intervals to define any association between dependent variable and independent variables. A p-value less than 0.05 was considered statistically significant.

An ethical approval was first sorted from the relevant college ethics board authorities such as the Departmental Research Coordinator at FNU and the College Research Ethics committee-FNU. Once the approval was granted an email was sent to FNU Dental Clinics, Deputy Head of Department of Oral Health, Clinical Director and the Clinical Coordinators to seek permission to access the records for the years 2013 and 2014.

\section{Results}

\section{Demographic characteristics of periodontitis patients}

Table 1 shows the demographic characteristics of periodontitis patients. The average age of patients was 46.8 years $(S D=13.3)$. The periodontitis patients seen among the age group 15-39-years old was $29.9 \%$, among the age group 40-64-years old was $61.8 \%$ and among the age group 65 years and above was $8.3 \%$. The male periodontitis patients seen were $42.8 \%$ and $57.2 \%$ were females. I-Taukei Fijians constituted $47.4 \%$ of the study population, $32.5 \%$ were Fijians of Indian Descent and 20.1\% represents individuals from other ethnic groups.

\begin{tabular}{|l|l|l|}
\hline Variable & $\mathbf{n}$ & $\%$ \\
\hline Age group & & \\
\hline $15-39$ & 108 & $29.90 \%$ \\
\hline $40-64$ & 223 & $61.80 \%$ \\
\hline 65 above & 30 & $8.30 \%$ \\
\hline Total & 361 & 100 \\
\hline Gender & 158 & $42.80 \%$ \\
\hline Males & 211 & $57.20 \%$ \\
\hline Females & 369 & 100 \\
\hline Total & 175 & $47.40 \%$ \\
\hline Ethnicity & 369 & $32.50 \%$ \\
\hline I-Taukei Fijian & 120 & $20.10 \%$ \\
\hline Indo- Fijian & & 100 \\
\hline Other & 175 & \\
\hline Total & & \\
\hline
\end{tabular}

Table 1: Demographic characteristic of periodontitis patients.

Demographic characteristics of periodontitis patients with and without systemic disease.

The demographic characteristics of periodontitis patients with and without systemic disease are summarized as in Table 2. The odds of having systemic disease were 3.5 times higher in 40-64-year-old patients than in the 15-39-year-old periodontitis patients (OR 3.5, 95\% CI 1.98-6.09, $\mathrm{p}=<0.001)$. Male periodontitis patients reported with $42 \%$ systemic disease and females reported with 58\% systemic disease. Systemic disease was higher in females than males; however, this was not statistically significant. The odds of having systemic disease were 1.9 times higher in the Fijians of Indian Descent than among the ITaukei Fijians (OR 1.9, 95\% CI: 1.17-3.11, p=0.026).

\begin{tabular}{|l|l|l|l|l|l|}
\hline Variable & $\mathbf{n}$ & $\begin{array}{l}\text { With- systemic disease } \mathbf{n} \\
\mathbf{( \% )}\end{array}$ & $\begin{array}{l}\text { Without-systemic disease } \\
\mathbf{n}(\%)\end{array}$ & $\mathbf{P}$ & $\begin{array}{l}\text { OR (95\% Cl) } \\
\text { Og } \\
\text { gro } \\
\text { up }\end{array}$ \\
\hline $15-39$ & 108 & $19(14.6)$ & $89(38.5)$ & $<0.001$ & 1 \\
\hline
\end{tabular}


Citation: Thomas A, Maimanuku LR, Mohammadnezhad M, Khan S (2018) Determinants of Systemic Diseases amongst Periodontitis Patients in Suva, Fiji. J Health Educ Res Dev 6: 254. doi:10.4172/2380-5439.1000254

Page 3 of 4

\begin{tabular}{|c|c|c|c|c|c|}
\hline $40-64$ & 223 & 95 (73.1) & $128(55.4)$ & & $3.48(1.98,6.09)$ \\
\hline 65 above & 30 & $16(12.3)$ & $14(6.1)$ & & $5.35(2.24,12.80)$ \\
\hline Total & 361 & 130 & 231 & & \\
\hline \multicolumn{6}{|l|}{ Gender } \\
\hline male & 158 & $55(42.0)$ & $103(43.3)$ & \multirow{3}{*}{0.81} & 1 \\
\hline Female & 211 & $76(58.0)$ & $135(56.7)$ & & $1.05(0.69,1.62)$ \\
\hline Total & 369 & 131 & 238 & & \\
\hline \multicolumn{6}{|l|}{ Ethnicity } \\
\hline I-Taukei & 175 & $50(38.2)$ & $125(52.5)$ & \multirow{3}{*}{0.026} & 1 \\
\hline Indo- Fijian & 120 & $52(39.7)$ & $68(28.6)$ & & $1.91(1.17,3.11)$ \\
\hline Others & 74 & $29(22.1)$ & 45 (18.9) & & $1.61(0.91,2.85)$ \\
\hline Total & 369 & 131 & 238 & & \\
\hline
\end{tabular}

Table 2: Demographic characteristics of patients with and without systemic diseases.

\section{Discussion}

The results of this study showed that systemic disease was the most in 40-64-year-old Fijians of Indian decent periodontitis patients, this was statistically significant. Female periodontitis patients showed higher presence of systemic diseases than the male periodontitis patients; however this was not statistically significant.

\section{Age distribution}

The age group in our study was divided into three groups, i.e. age group 15-39 years, 40-64 years and 65 years and above. The age group 15-39-year olds reported $29.9 \%(n=108)$ periodontitis patients with systemic diseases, the age group 40-64-year olds reported $61.8 \%$ $(n=223)$ periodontitis patients with systemic diseases and the age group 65 years and above reported $8.3 \%(n=30)$ periodontitis patients with systemic diseases.

The odds of having systemic disease were 3.5 times higher in 40-64year-old patients than in the 15-39-year-old periodontitis patients (OR $3.5,95 \%$ CI 1.98-6.09, $\mathrm{p}=<0.001$ ). The younger age group 15-39 years had $14.6 \%$ systemic disease while in the older age group 40-64 years the number of systemic disease increased significantly to $73.1 \%$. Similarly, the study by Georgiou et al. [4], reported the prevalence of systemic disease was $40-50 \%$ among the younger age group while the prevalence of systemic disease increased significantly in the old age group to $70-71.3 \%$. In a study by Nazir [9], it was stated that periodontal disease causes increased risk of cardiovascular diseases among individuals above 65 years of age. In a study by Pattnaik et al. [10], it was reviewed that prevalence of severe periodontitis was higher among individuals aged 65 years and above than the age 20-29 years. The prevalence of risk factors increases with age along with its cumulative effects. The relationship between population ageing and growing burden is established by the association between morbidity and loss of function and biological age. However, this association is not fixed; therefore there is scope in health promotion and disease prevention among elderly individuals. Ageism, complex multimorbidity and inadequate access to age appropriate care is aggravated by factors like insufficient security income, social protection and user fees leading to further complications in effective intervention among the older populations [11].

In this study, the age group 40-64 years showed highest predominance among heart diseases (68.1\%) and diabetes $(79.3 \%)$. This could be because total number of periodontal patients seen in our study, among the age group $40-64$ years was $61.8 \%$ and among the age group 65 years and above was only $8.3 \%$ and also according to the Fiji Islands Health System Review [12] it was reported that the inhabitants living beyond 50 years of age were $60 \%$ and living beyond 60 years was only $8 \%$ in Fiji. In a developing country like Fiji, the elderly is not abandoned but due to inadequate resources the healthcare is insufficient [13].

\section{Gender distribution}

In this study, the total number of male periodontitis patients were $42.8 \%(\mathrm{n}=158)$ and the number of female periodontitis patients were $57.2 \%(n=211)$. In a study by Alam et al. [14] it was stated that males show more predilection over females in periodontal diseases. Factors such as poor oral hygiene, reduced positive attitudes toward oral health, and dental-visit behavior among males were identified as responsible for the male predilection as any genetic factor. Also, that the important factor to be considered is that women have varied periodontal problems due to hormonal changes in various decades of life. However, we cannot predict the outcome of treatment plans depending on the gender predilection for periodontal diseases because the pattern of disease progression is different in males and females [14]. In the present study, male periodontitis patients with systemic diseases was $42 \%(n=55)$ and female periodontitis patients with systemic diseases was $58 \%(n=76)$. The study showed higher presence of systemic diseases among the female periodontitis patients than male periodontitis patients; however this was not statistically significant. Similarly, in a study by Bhateja [6] no statistical association was seen between gender and periodontitis patients with systemic disease. According to the Fiji Ministry of Health [15] reports it was reported that $61 \%$ of females had more diabetes than males $39 \%$. And also in the 
Citation: Thomas A, Maimanuku LR, Mohammadnezhad M, Khan S (2018) Determinants of Systemic Diseases amongst Periodontitis Patients in Suva, Fiji. J Health Educ Res Dev 6: 254. doi:10.4172/2380-5439.1000254

Page 4 of 4

STEPS survey it was reported that the moderate to high risk of developing non-communicable diseases was $97 \%$ among men and $98 \%$ among women in Fiji and it was also identified that the risk significantly increased with age. Females can have higher probabilities of getting diabetes and heart diseases in Fiji due to overweight and obesity. Also, $85 \%$ of women consume below five helpings of fruits and vegetables per day in Fiji [16]. Nutrition is an important factor in maintaining oral and periodontal health along with general health. Vegetables and fruits are regarded as the principal dietary sources of anti-oxidants like vitamins C. Periodontitis may be prevented by the reduction of free radicals and oxidative stress in the periodontal tissues through the consumption of potassium rich vegetables and fruits [17]. All these factors could have been the reason female periodontitis patients showed a higher number of systemic diseases than males.

\section{Ethnicity distribution}

The ethnic groups in this study were I-Taukei Fijians $47.4 \%(n=175)$, Fijians of Indian Descent $32.5 \%(n=120)$ and the other group of ethnicities $20.1 \%(n=74)$ which consisted of all the ethnic groups of people excluding I-Taukei Fijians and Fijians of Indian Descent.

The odds of having systemic disease were 1.9 times higher in the Fijians of Indian Descent than among the I-Taukei Fijians (OR 1.9, 95\% CI: 1.17-3.11, $\mathrm{p}=0.026$ ). This could be due to the fact that Fijians of Indian Descent are immigrants originating from the Indian subcontinent who are at a higher risk of development of noncommunicable diseases like diabetes, heart diseases due to rapid nutrition and lifestyle transitions, lower health seeking behavior, delayed diagnosis due to language barriers and religious and sociocultural factors [18].

This study thus showed significant association between age and ethnicity among periodontitis patients with and without systemic diseases. Further prospective and interventional studies are required to determine exact cause of association as this is a retrospective descriptive study [19-21]. The study was on periodontitis patients seen at FNU Dental Clinics and hence does not represent the entire Fijian population. The study can be utilized by FNU Dental Clinics to improve oral health especially among periodontitis patients with systemic disease and also to improve their patient data recording systems and to carry on further research studies to determine the exact cause of the link between periodontitis and systemic diseases.

\section{Conclusion}

The study concluded that systemic disease was the most in 40-64year-old patients than among all the other age groups, this was statistically significant. Female periodontitis patients showed higher presence of systemic diseases than the male periodontitis patients; however this was not statistically significant. And the Fijians of Indian Descent showed higher number of systemic diseases than the I-Taukei Fijians, this was statistically significant.

\section{Conflict of Interest}

There is no any conflict of interest.

\section{References}

1. Sukumaran A (2014) Periodontal Disease, Dental Caries and Hypersensitivity- A Millennial view, Singapore, MIMS Pvt Ltd.

2. Vos T, Flaxman AD, Naghavi M, Lozano R, Michaud C, et al. (2012) Years lived with disability (YLDs) for 1160 sequelae of 289 diseases and injuries 1990-2010: a systematic analysis for the Global Burden of Disease Study 2010. Lancet 380: 2163-2196.

3. Albandar JM, Brunelle JA, Kingman A (1999) Destructive periodontal disease in adults 30 years of age and older in the United States, 1988-1994. J Periodontol 70: 351.

4. Georgiou TO, Bartold PM, Marshall RI (2004) Prevalence of systemic diseases in Brisbane general and periodontal practice patients. Aust Dent J 49: 177-184.

5. Agarwal A, Gupta ND (2013) Prevalence of Self-Reported Medical Conditions and Drugs Used in Periodontally Compromised Geriatric Population. J Periodontal Implant Dent 5: 66-70.

6. Bhateja S (2012) High prevalence of cardiovascular diseases among other medically compromised conditions in dental patients: A retrospective study. J Cardiovasc Dis Res 3: 113-116.

7. World Health Organization (2012) WHO Country Co-operation Strategy for Fiji 2013-2017.

8. World Health Organization (2014) Health Profile Fiji.

9. Nazir MA (2017) Prevalence of periodontal disease, its associations with systemic diseases and prevention. Int J Health Sci 11: 72-80.

10. Pattnaik NK, Das SN, Biswal BN (2017) Cardiovascular Diseases and Periodontal Diseases: Review and Update. Int J Sci Study 5: 239-244.

11. Prince MJ, Wu F, Guo Y, Robledo LMG, Donnell MO, et al. (2015) The burden of disease in older people and implications for health policy and practice. 385: 549-562.

12. World Health Organization (2011) Fiji Islands health system review. Manila: WHO Regional Office for the Western Pacific 4: 140.

13. Sharma N (2010) Opening address by Neil Sharma, the Minister for Health, at the 2010 Fiji Health Symposium, Suva.

14. Alam MDN, Mishra P, Chandrasekaran SC (2012) Gender Basis of Periodontal Diseases. Indian J Basic \& Appl Med Res 2: 128-135.

15. Ministry of Health (2015) Fiji Annual report.

16. Asian Development Bank (2015) Fiji Country Gender Assessment 2015. Accessed on: 2015.

17. Yamori M, Njelekela M, Mtabaji J, Yamori Y, Bessho K (2011) Hypertension, Periodontal Disease, and Potassium Intake in Nonsmoking, Nondrinker African Women on No Medication. Int J Hypertens, p: 5.

18. Misra A, Khurana L (2011) Obesity-related non-communicable diseases: South Asians vs. White Caucasians. Int J Obes (Lond) 35: 167-187.

19. Ministry of Health (2004) Fiji Oral health survey.

20. World Health Organization (2015) Non-Communicable diseases progress monitor. Geneva, Switzerland: World Health Organization.

21. World Population Review (2017) World Population by Country. 